\title{
GIS-BASED DISASTER WARNING SYSTEM OF LOW TEMPERATURE AND SPARE SUNLIGHT IN GREENHOUSE
}

Ruijiang Wei ${ }^{1,2, *}$, Chunqiang $\mathrm{Li}^{1,2}$, Xin Wang ${ }^{1,2}$

${ }^{1}$ Hebei Provincial Institute of Meteorology, Shijiazhuang, Hebei Province, P. R. China 050021

${ }^{2}$ Hebei Provincial Key Lab for Meteorology and Eco-environment, Shijiazhuang, Hebei Province, P. R. China 050021

* Corresponding author, Address: Hebei Provincial Institute of Meteorology, Shijiazhuang 050021, Hebei Province, P. R. China, Tel: +86-311-85218904, Fax: +86-311-85218901, Email: hbkyswrj@sina.com

Abstract: The disaster that low temperature and spare sunlight occurred in North China is a major weather hazards to the sunlight greenhouse vegetable growing. The establishment of disaster warning system of low temperature and spare sunlight for greenhouse is of great significance to the disaster mitigation and prevention. According to the climate characteristics of Hebei Province and regional distribution of greenhouse, under the support of GIS and computer technology, using $\mathrm{C} / \mathrm{S}$ structure, the early warning system was developed with multi- functions such as data acquisition automatically, disaster early warning, documentation services generating, early warning test and so on. This paper introduced briefly about the system operating environment, structure, function, operational process, as well as disaster warning results displaying. Operational applications showed that GIS-based system can describe the occurrence, distribution and intensity of disasters objectively, also provide a scientific basis for disaster prevention and mitigation.

Keywords: Sunlight Greenhouse, Low Temperature and Spare Sunlight, Disaster Early Warning, Computer-system, GIS

Hebei Province is located in the North China Plain, where upper air is controlled by northwest air current generally in autumn and winter and the solar radiation resources is quite rich, thus it is able to provide the natural energy for the sunlight greenhouse vegetables production(Su Jianqin et al., 1996). The sunlight greenhouse area has already been amounted to 200,000

Please use the following format when citing this chapter:

Wei, R., Li, C. and Wang, X., 2009, in IFIP International Federation for Information Processing, Volume 293, Computer and Computing Technologies in Agriculture II, Volume 1, eds. D. Li, Z. Chunjiang, (Boston: Springer), pp. 107-114. 
hectares until the year of 2006, the second ranked in the whole nation, since 1996 the first sunlight greenhouse was established in Hebei Province. Up to now, its productions of vegetables for major cities, such as Beijing and Tianjin, have had a solid market share. But as a result of both geographical location and climatic characteristics, it is easy to appear the overcast (snow or fog) weather during the sunlight greenhouse vegetables growing period in the central and southern regions of Hebei Province, which causes the occurrence of disasters that low temperature and spare sunlight, and consequently brings a great loss to the vegetables productions ( Zhao Yuguang et al., 2004; Huazhong Agricultural University, 1986; Wei Ruijiang, 2003).

It is not only of urgent necessary for the modern agricultural production to reinforce the disaster mitigation and prevention of low temperature and spare sunlight in greenhouse, but also an important aspect of meteorological service for agriculture production. The rapid development of the modern information technology, especially geographical information system (GIS) technology, makes it quite possible that the real-time dynamic monitoring and early warning for the occurrence region, intensity and scope of disasters that caused by low temperature and spare sunlight.

Based on the disaster indexes of low temperature and spare sunlight and real-time meteorological data, as well as future numerical weather forecast products, early warnings about the disaster would be carried on, and also provided the service information for the disaster prevention and mitigation, which is capable to describe the occurrence intensity and regional distribution of disasters.

\section{OPERATING ENVIRONMENT}

Hardware environment: CPU is Pentium IV or above, memory is $512 \mathrm{MB}$ or more, hard disk space $80 \mathrm{G}$ or more.

Software environment: OS is Windows 2000 or above.

\section{SYSTEM STRUCTURE}

System software was developed by $\mathrm{C}^{++}$language, and adopting the frame of $\mathrm{C} / \mathrm{S}$, including server and client of two parts. The server is consisted of two parts, one is database which using SQL 2000 Enterprise Edition to collect and store various data that systems required for the operation; the other is data synchronization calculation module, which works at the fixed time every day, collects the necessary data automatically, and stores the data into the database, all fully performed automatically without user intervention. 
The client provides users with an interactive interface, by which the operations would be carried on, such as information inquiry, disaster early warning, early warning prove, services document generation and so on. The system structure was illustrated in Fig. 1.

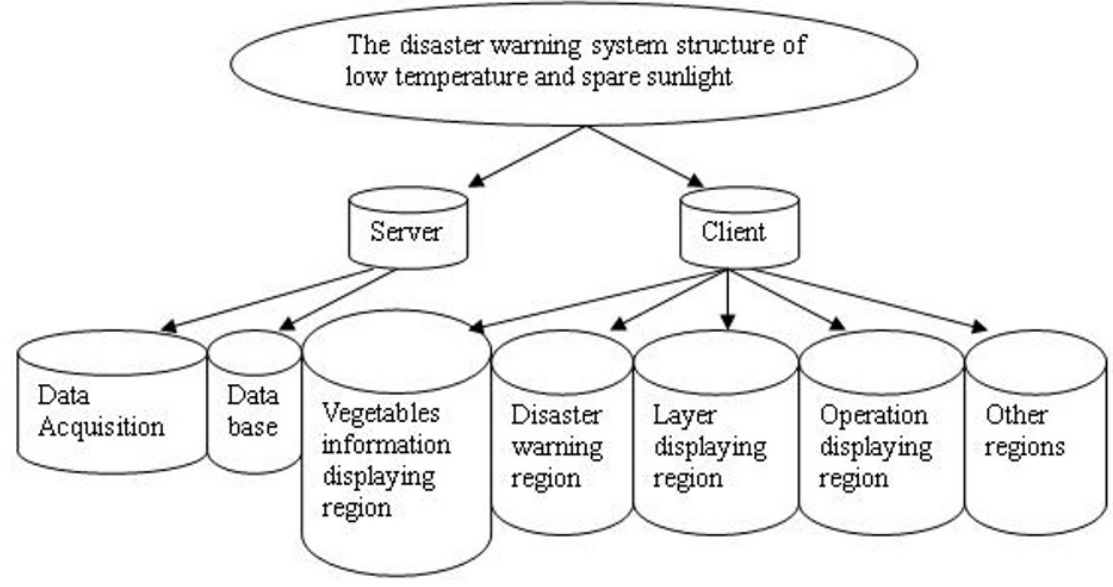

Fig.1. The structure of system for low temperature and spare sunlight

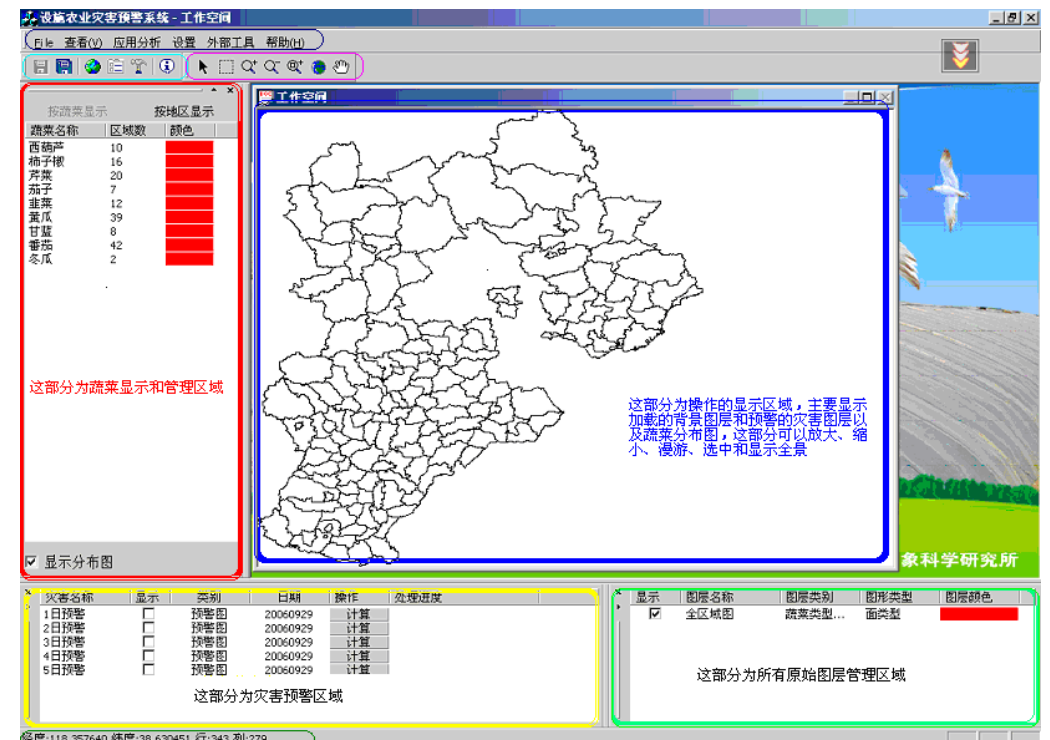

Fig. 2. The main client interface

Fig.2 shows the main client interface, including four major parts and several others. The major are as follows: vegetables information displaying, with red marked on the main client interface, shows all types of vegetables 
existed in the system and their spatial distribution; disaster warning with yellow marked, rolling early warning day by day in future 5 days would be implemented; layer displaying with blue marked is to load the background layer and the results of early warning as well as distribution map of vegetables; and operation displaying with green marked shows the names, types and colors of all layers existed in system. Others include menu, main toolbar, ordered toolbar and status bar.

\section{SYSTEM FUNCTION}

The block diagram of system function is given in Fig. 3. Seven major functions of the system are as the following:

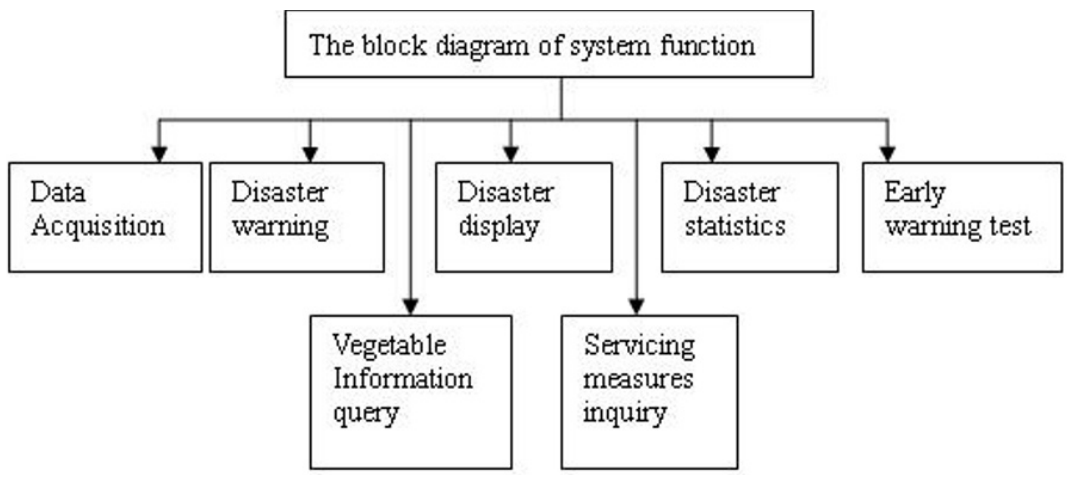

Fig.3: The block diagram of system function

(1)Data Acquisition: This module which is installed on the server would be activated at the fixed time every day automatically in order to acquire daily meteorological data on the LAN (local area network) and to store them in the database. The data include daily sunshine hours, minimum and maximum temperature observed in each station of the province as well as daily numerical weather forecast products.

(2)Vegetable Information query: This module shows vegetable types and spatial distribution of sunlight greenhouse located in all counties of the whole province. It displayed in two ways, one is display by vegetables and another is by regions. The former display shows the distributing regions of different types of vegetables, and the latter shows the types of the sunlight greenhouse vegetables in every county, indicated with the pie chart, and several kinds of the vegetables would be divided into equal parts in a pie chart.

(3)Disaster warning: It's the chief module of the system, besides to read the vegetables information in the database, the current live weather 
information and the future numerical weather forecast information, its function is to identify automatically whether it to occur or not a disaster, its regions and intensity in the future five days in response to the disaster indexes of low temperature and spare sunlight for different types of vegetables. Disaster early warning is divided three classes, i.e., light, moderate and severe, generating the early warning map (including disaster intensity and disaster regions) and vegetables growth and development status as well as the "word" format document about management measures automatically too.

(4)Disaster display: It shows the background layer, result layer of disaster early warning and the map layer for vegetables distribution, with the functions of picture zooming, roaming, checking and displaying panorama features and so on.

(5)Servicing measures inquiry: We can use this module to check the different type vegetables suitable condition, the potential disaster, results of disaster and the defense management measures in two ways, which is follow as "the vegetables development stages as the sequence" and "the ten-day period as the sequence". As to them, we may increase, modify, delete arbitrarily. "The vegetables development stages as the sequence", as the name implies, takes the different development stages of vegetables as the sequence such as the seeding, planted, flower and harvested. "The ten-day period as the sequence" is implemented according to the time sequence, such as in early January, mid-January.

(6) Disaster statistics: It would count the times of disasters that low temperature and spare sunlight of different extent occurred in counties at random period. In addition, it would record the occurred time of disasters by the way the same as number of times.

(7) Early warning prove: It would take the number of times of disasters and the actual number as a comparison with the intention of testing results of early warning.

\section{EARLY WARNING FLOW-CHART}

First, each kind of data which system needs to be transferred, including the vegetable types of various counties (cities) in Hebei Province, the disaster indexes of low temperature and spare sunlight, the daily sunshine hours observed and daily numerical weather forecast products in the future of five days. Then computation would be carried on for the whole 142 sites of the province according to the disaster early warning indexes, to determine whether it occurs or not a disaster. Early warning output uses Hebei Province map as background and generates pictures. The system can automatically 
search for the current development stage of vegetables and service measures in service measure database and put them into the WORD format documents with generating early warning results. Finally the service product would be formed through the manual edition. The early warning flow is shown in Fig. 4.

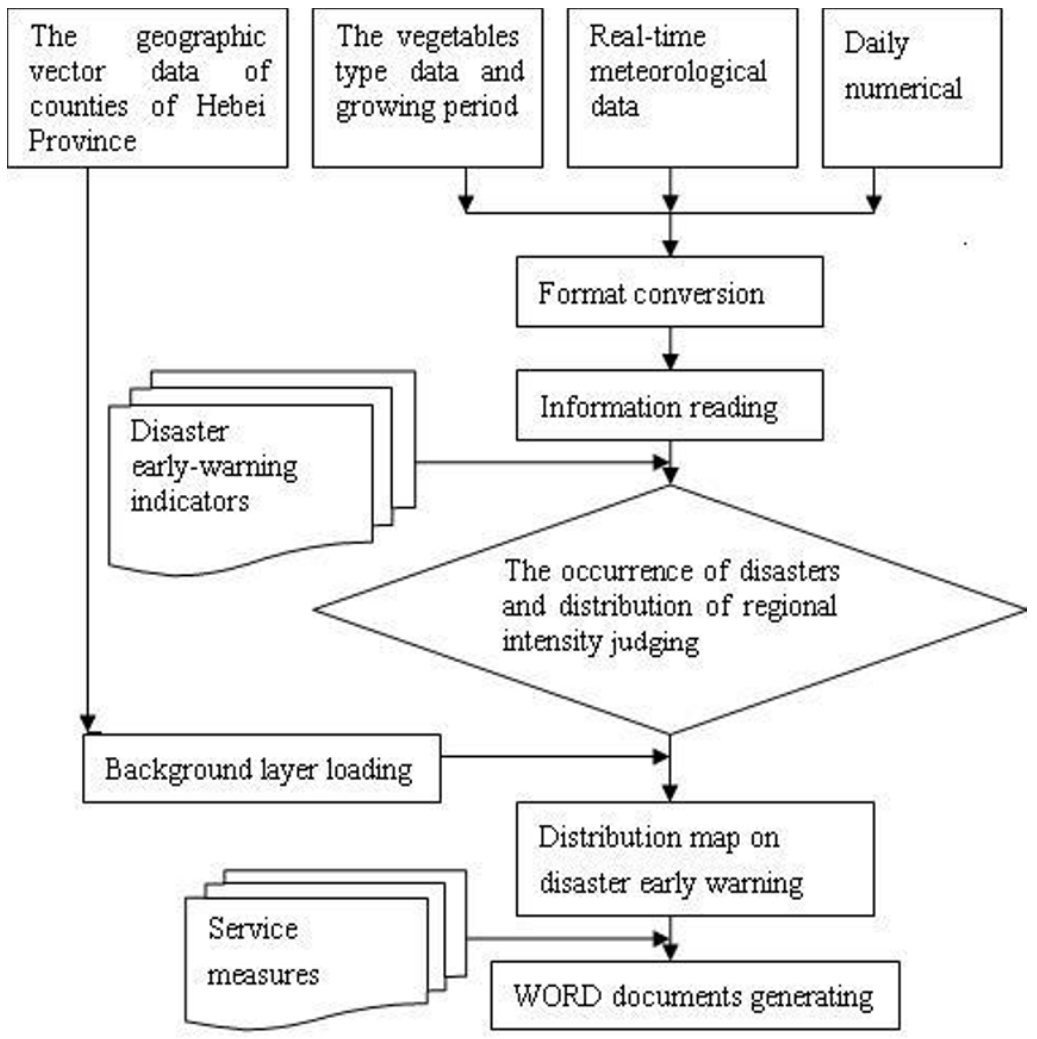

Fig.4. The flow diagram of the early warning system

\section{DISASTER EARLY WARNING RESULT DISPLAY}

Geographical data set comes from the national basic geographic information system center. Under the technical support of GIS, the geographic data of Hebei Province can be conversed, overlay, stitched, tailored and formed geographical background data set including 142 counties (cities) of Hebei Province. The regions out of the province boundaries are defined as 0 , the regions that cities and counties within the Provincial boundaries are filled up with code. This system can transfer the regional vector data of every administrational counties (cities) of Hebei Province, with Arcview SHP form and Gauss- Craig projection. 
When the disaster that low temperature and spare sunlight is identified by the indexes, it is necessary to show the occurrence region and its intensity. When there are different levels of early warning of disasters, the regions corresponding to the county (city) would be given the appropriate color (No disaster, no color display) based on the early warning levels of sites and by using geographical information technology to achieve the purpose of disaster warning. For example, the early warning result of the next three days on November 23, 2006 was illustrated in Fig.5.

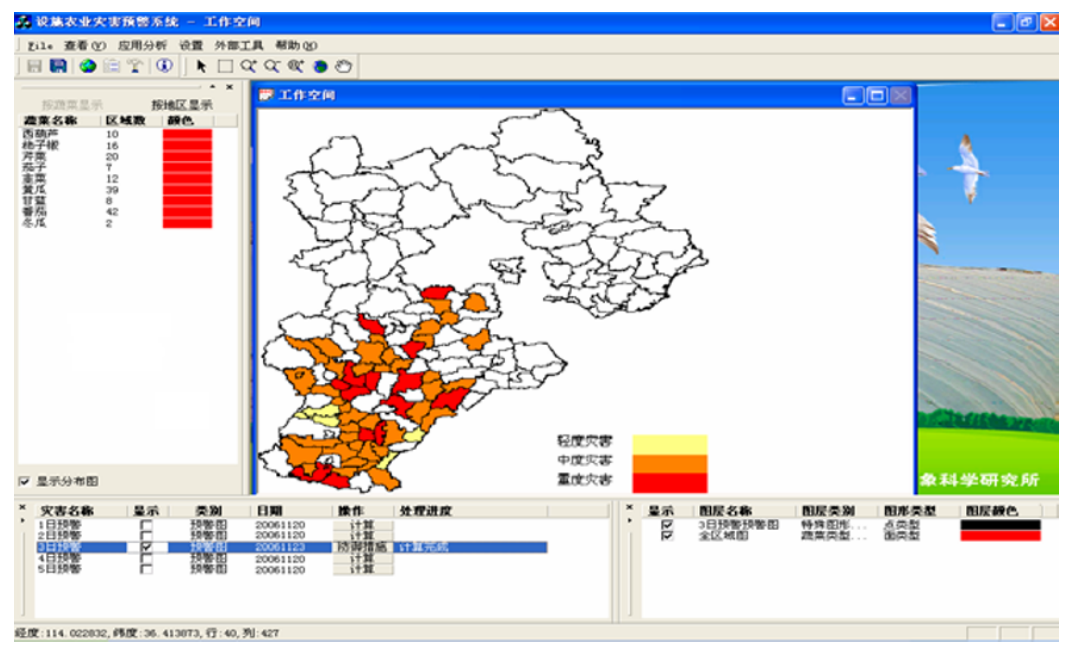

Fig.5. The early warning result of the next three days on November 23, 2006

\section{CONCLUSIONS}

GIS-based Disaster Warning System of Low Temperature and Spare sunlight in greenhouse, using $\mathrm{C} / \mathrm{S}$ structure, with the functions such as meteorological data acquisition, the information inquiry, disaster warning, early warning test, document generation services, servicing measures inquiry, disaster statistics, early warning test and so on. The operational application of the system made the meteorological service quality and effectiveness, as well as the automation of disaster early warning have been improved.

The operational service of the system might provide a scientific basis for decision-making to the agricultural production department and leaders directing the agricultural production.

According to the development of modern agricultural facilities, the system will need to be improved in order to play a major role much better in the meteorological services for agriculture. 


\section{REFERENCES}

Huazhong Agricultural University.Vegetable Pathology.Agricultural press: 1986,163-163

Su Jianqin,Cheng Shulin,Guo Yingchun. Hebei Climate. Meteorological press:1996,1-2

Wei Ruijiang. The Disaster Grades of Low Temperature and Spare Sunlight in Greenhouse. Meteorological Science and Technology. 2003, 31(1) : 50-53

Zhao Yuguang,Li Jiangbo,Kang Xiyan. Fog Forecast of Local Country in Hebei Province with PP Method. Meteorological Monthly. 2004, 30(6) : 43-47 